\title{
Climatic analysis methodology of vernacular architecture
}

\author{
I.J. Gil Crespo, M.M. Barbero Barrera \& L. Maldonado Ramos \\ Universidad Politécnica de Madrid, Spain
}

\begin{abstract}
Vernacular architecture has demonstrated its perfect environmental adaptation through its empirical development and improvement by generations of user-builders. Nowadays, the sustainability of vernacular architecture is the aim of some research projects in which the same method should be applied in order to be comparable. Hence, we propose a research method putting together various steps. Through the analysis of geographical, lithology, economic, cultural and social influence as well as materials and constructive systems, vernacular architecture is analyzed. But, all this information is put together with the natural landscape (topography and vegetation) and the climatic data (temperature, winds, rain and sun exposure). In addition, the use of bioclimatic charts, such as Olgyay or Givoni's, revealed the necessities and strategies in urban and building design. They are satisfied in the vernacular architecture by the application of different energy conservation mechanisms, some of them are shown by different examples in this paper.
\end{abstract}

\section{INTRODUCTION}

Vernacular architecture has been revised for two decades as an expression of our cultural heritage. To be exact, its constructive and typological characteristics have been successively reviewed from different and innovative points of view as architectural sustainability that complete the traditional social-cultural point of view (Rudofsky 1968, Oliver 2003). Vernacular architecture is an example of the adaptation of construction to the environment and to the place through an empirical and generational experience and learning. And, it is the latter which has allowed the improvement of the systems. The natural and human environmental adaptation is one of the teachings of the study of vernacular architecture. This knowledge is essential for preservation and maintenance of this type of architecture which implies as well the search for solutions for adaptation to the new functional and technical standards. Since 20 years ago, the traditional point of view in terms of history, typology and folk of vernacular architecture has been reconsidered. Vernacular architecture's energetic behavior about its adequacy has been researched by several authors (Alp 1991; Gavieta 1991; Matsubara, Nakase \& Horikoshi 1991; Özdeniz 1991; Al-Hinai, Batty \& Probert 1993; Jingxia 1996; Cardinale, Micucci \& Ruggiero 2003; Singh, Mahapatra \& Atreya 2008; Vissilia 2009; Zhai \& Previtali 2010).

In the case of Spain, several energy analysis on traditional industrial buildings have been made (Mazarrón \& Cañas 2009, Ruiz, Cid \& Cañas 2010, Saá et al 2011, Saá et al 2012), but also there are researches about residential buildings (Cañas \&
Martín 2004, Cárdenas, Maldonado, Barbero \& Gil 2008, Luxán et al 2011, Barbero, Gil, Maldonado \& Cárdenas 2013, Gil Crespo 2014).

\section{FACTORS TO TAKE INTO ACCOUNT}

The analysis of climatic adequacy of vernacular architecture is based on several factors which should be taken into account. They conforms the knowledge and comprehension of both the natural and human media as well as the architectural expression.

Vernacular architecture forms and elements' links are derived of its adaptation and development in a specific place-locus- and it is expression of its human, cultural and physical characteristics. Geology, relief, climate, history, economy and culture affects to the building materials and systems as well as the architectural type which is the result of the function-use and in the bioclimatic aspects of the site architecture.

It is clear that environment influences architecture, in such a way that architecture is developed to compensate its scope. This relationship affects, first, to constructive aspects. In a pre-industrial stage, in where there are no technical or material standards, the diversity of the architecture is unified and has a traditional and vernacular character that it is kept or modified depending on the empirical experience of the inhabitants. Architecture takes maximum advantage of the environment's possibilities with the optimal economy of means. Building materials are taken near the construction site. The material and the construction technique 


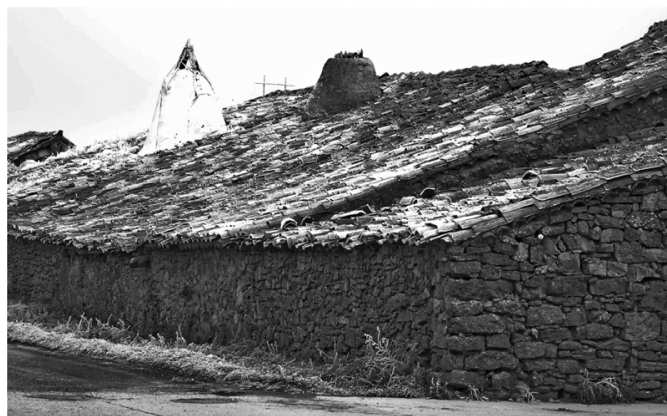

Figure 1. The forms of the architecture are adapted to the natural and human media. Dwellings in Villaciervitos (Soria, Spain) are grouped in rows. They have a big roof with low slope. Northern walls are low and thick and they have not hollows. In the interior there are coexistence of humans and animals. The big chimney (called chimenea pinariega) covers the whole of the space of the cook room (Gil Crespo).

determine the architecture. However, it is proven that the combination of the different natural and human characteristics of the environment has determined the constructive, formal and functional traditions, e.g. there are stone architecture if there is stone in the place and the inhabitants know the work of stone-cut.

This architecture is built by the owners in the rural environment and it has been made employing an elemental pre-industrial technology. It has followed models based in the tradition, which has been reproduced and developed along time in a geographic region with all its characteristics. The result is a rational typological, functional and constructive characterization: architecture serves to the necessities and the economical possibilities of the society. This rational sense is reflected in the simplicity of the inner distribution in dwellings or auxiliary buildings, but also in the solutions of the traditional constructive techniques or the variety on bioclimatic resources which link the man with the environment through vernacular architecture.

Based on these assumptions, the delimitation the geographical field of study is the first task. This delimitation is mostly determined by geographical, social, economical or historical characteristics. In this sense, as preliminary analysis, it is necessary to define the knowledge about the beneficial and adverse aspects of the environment in terms of geology, lithology, relief, biology and, mainly, climate. The tools for this analysis are the different synoptic maps and also the data about the microclimatic normal values: annual, monthly and daily maximum and minimum average of temperature and humidity, average of rains, solar radiation and the numbers of days with rain, storm, fog or frost.

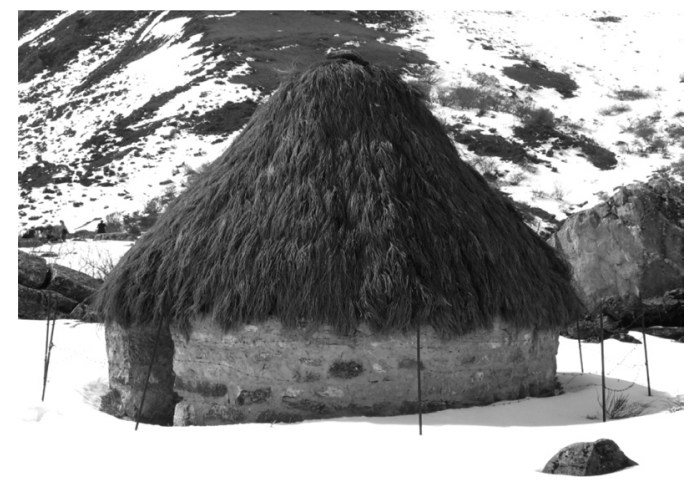

Figure 2. Braña in Asturias. Stone walls with straw roof in which the relation among the building material, economy and architecture is clear (María del Mar Barbero Barrera).

These data are the average of a large time lapse of a minimum of 10 years, being convenient for relevance those referred to 30 years.

Geological and lithological characteristics influence on the use and work of constructive materials and techniques. Relief and rivers web study help to know the situation of the settlements in terms of water supply or agricultural use, the optimal orientations for sun radiation of shading protection. At the same time, these factors influence in the direction of the winds and the formation of fogs. So, architecture will require mechanisms to protect of these climatic factors.

Geobiology - natural fauna and flora, agricultural and cattle landscape - analysis is important because its results could be used to know the form and the function of several auxiliary buildings, the link between human and animals and the employ of vegetal roofs.

At last, it is important to know the traditional way of life in each studied region because this relationship between natural and social environments. In the case of Spain, there are several important historical factors to take into account, as the predominance of minifundia - smallholding - or latifundia as agricultural exploitation. The influences of the diverse cultures - Celtic or Iberian, Roman, Visigothic, Islamic - of each region are different. This item explains some differences in the social, economical or folk way of life that are essential to know the typological function of dwellings or architectural elements as windows, balconies and others. The cultural and historical past has relevance in the forms of vernacular architecture and also in the predisposition of the inhabitants to choose the materials and techniques.

Thus, the knowledge of all these factors that determine the place and its influence on the 


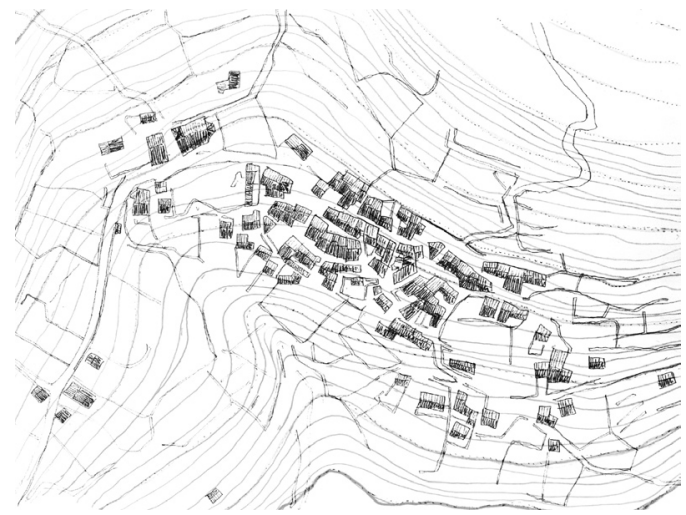

Figure 3. Urban settlement analysis in Gredos range (Gil Crespo 2011)

architecture have to be afforded by the analysis of the environment and climatic factors. Climatic factors such as wind, rain, temperature and solar radiation do not only define the situation of the settlements near water sources, but also the disposition and characteristics of the vernacular buildings. The bioclimatic chart of Olgyay (1998) is used to value the urban adequacy of the settlement to the climatic characteristics. This tool also serves to know the adequacy of the adopted strategies when there are modifications in the planning and in the historical changes of the town. In this sense, the employ of Olgyay's bioclimatic chart allows to value how these alterations have been able to affect or not the modern urbanism and its influences on the traditional buildings. This analysis is completed with the study of the hygrothermal (temperature and humidity) behavior of the interior of vernacular dwellings by means of Givoni's chart (1969).

\section{METHOD OF ANALYSIS OF ENERGY PERFORMANCE OF THE VERNACULAR ARCHITECTURE}

A deep knowledge of the natural and human conditions of the geographical region which is the aim of the research is previous to the architectonical analysis. The latter is developed in several levels or scales: territory, urban, building as well as their elements. Cartography, plans and photography are the basic tools used in this stage. The territory and urban scale use topographical, ortho-photographs and digital models of the land as well as cadastral plans and historical and current aerial photographs. They allow us to research the type of settlements as well as the use of the public-private spaces as well as the use of solar radiation through its historical evolution, among others.
Based on the architectonical scale, the planimetry of the building-layout, elevation, sections and relation between the building and the urban space - is the common used tool which allows us between a comparative method to establish a invariants and the architectonical types based on a classification of the type and morphology of the ensembles. Constructive details of representative elements complete the architectural analysis.

On the other hand, indoor mechanisms are analyzed. It implies the analysis of the tools that were used for solar protection and collection of solar energy, lighting as well as the use of winds, breezes and rainfall according to the specific requirements of the place and the inhabitants.

Givoni's bioclimatic chart (1969) is used to investigate the influence of each parameter and evaluate the adequacy of the strategies. It is a practical tool for the design and the analysis of the indoor environment based on the experience of the circumstances in which inhabitants are in comfort conditions taking into account parameters such as the latitude, human group, physical activity, clothes and age, among others. At the same time, it implies that comfort area should be defined according to the specific characteristics of the region in which the building is placed and the type of population. In these circumstances in which the physical wellbeing is not achieved due to the temperature or the humidity conditions, Givoni's chart provides some bioclimatic strategies to solve the deficiency.

The analysis by the Givoni's chart is based on the introduction of different points (dry temperature and humidity) which defined the normal climatic values of a region. In a preliminary analysis of general character, the introduction of annual or seasonal average values can give us an idea over the building adaptation to the climate. However, it is interesting to develop a complete analysis in which daily and monthly variations are taken into account. In this way, hygrothermal variations of the place and its influence on the buildings as well as the necessity to apply differential strategies as a function of the day or the season can be analyzed. In this way, natural hygrothermal conditions can be guaranteed the welfare inside the building, in kind climates. However, conditions can be outside the comfort area or admissible comfort area in specific moments or situations. Regarding this, in Spanish climate, it is frequent that natural ventilation should be necessary in summertime conditions; while the strategy can be the opposite in wintertime and, in this case, the protection could be the predominant strategy, even with the requirement of active systems of conditioning.

Hence, the building analysis will be bound not only to the previous analysis of the architectural parameters which defined it but also to the territorial 


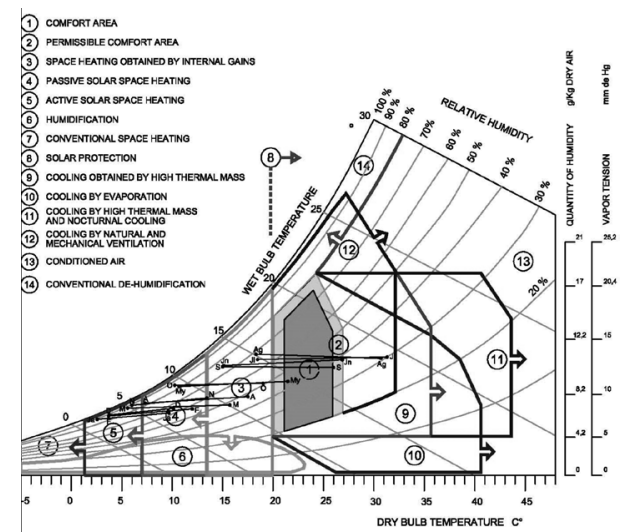

Figure 4. Simplified Givoni's bioclimatic chart from Madrid in which monthly maximum and minimum temperatures and humidities are drawn. As it can be observed, cooling by natural and mechanical ventilation is required in central hours of the day in July and August; in wintertime, passive solar heating can compensate differences between day and night to achieve comfort conditions (credits: Luxán et al 2009).

and urban ones. Through them we should analyzed the way in which architecture and its elements (shape, size, situation and construction as well as some specific elements such as windows, balconies, eaves, roofs or flat roofs...), its distribution and type (compacted or dispersed, layout around courtyards...) or even its urban ensemble (orientations, solar obstruction or capitation) as an answer to the necessities of the climatic region in which is placed.

\section{ENERGY CONSERVATION MECHANISMS IN SPANISH VERNACULAR ARCHITECTURE: THREE CASES OF STUDY}

Following the analysis of three architectural types, placed in different geographical regions, are exposed. They summarize different papers published last years by the authors (Maldonado, Castilla, Vela \& Rivera 2001, Cárdenas, Maldonado \& Gil 2007, Barbero-Barrera 2007, Cárdenas, Maldonado, Barbero \& Gil 2008, Gil Crespo 2011, Barbero, Gil, Maldonado \& Cárdenas 2013, Gil Crespo 2014).

\subsection{Dry warm subtropical climate: Eastern Canary islands}

Eastern Canary Islands (Lanzarote and Fuerteventura) show a warm climate which is characterized by the absence of thermal and humidity oscillation, without rainfalls and a continuous and strong wind. The factors that determine the climate are the sub-

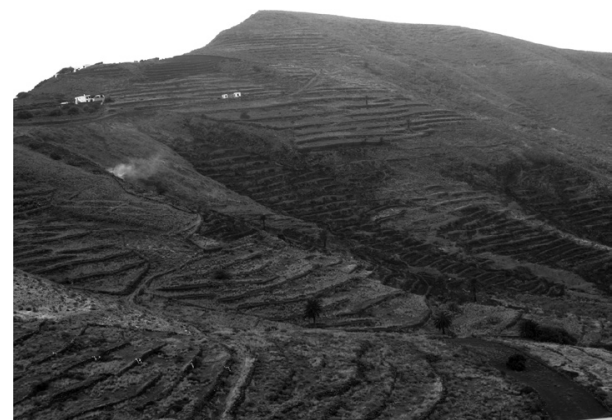

Figure 5. Dry and hot landscape in Lanzarote (María del Mar Barbero Barrera).

tropical latitude, the insularity and the influence of Azores' anticyclone, trade winds, cold oceanic current and the topography of the island as well as the proximity to Africa and to the Sahara's dessert.

In this region, dwellings are distributed around the courtyards which are oriented towards southeast to take advantage of the solar radiation and, mainly, to protect the construction against the characteristics winds of these islands. The most of the windows are placed leeward (southeast) while windward walls are commonly opaque. The high temperature justifies the height of the roofs to benefit ventilation and the ascension of the hot air. While the low precipitation is used by the water gathering and conduction in the flat roofs which is conducted to the auxiliary constructions for its storage and preservation.

\subsection{Cold climate of mountain regions}

On the opposite, in a cold or mountain climate, dwellings are compacted and gathered. The slopes of the roof depend on the amount of rainfall and its type (rain or snow). In this type of regions, with plentiful rainfalls, eaves are huge to move away the water from the construction; while windows are oriented towards south, east or southeast for solar collection although their limited dimensions show that the predominant strategy is protection. At the same time, small ceilings preserve the hot air while, in a stockbreeder economy, the presence of animals indoor is common to take advantage of them in wintertime (Gil Crespo 2011).

\subsection{Underground architecture}

Other of example of architectural adaptation to the climate is the caved architecture as cavedwelling or as underground dwelling (Cárdenas, Maldonado, Barbero \& Gil 2008). In this case, the thermal inertia of the land is used to compensate 


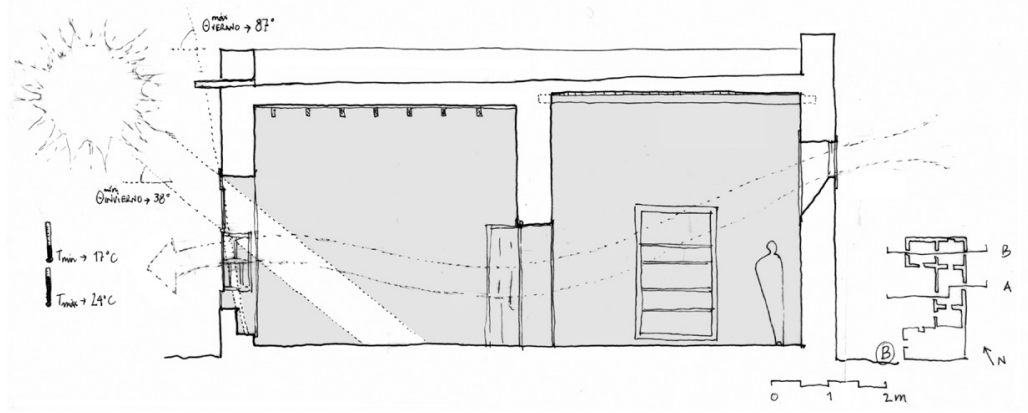

Figure 6. Section of a house in Mácher, Lanzarote, where the indoor conditioning system is explained. Air crossing is used as strategy to reduce the temperature in summertime while the glasses at the top of the windows controls the solar radiation and heating of the space (drawing by I.J. Gil Crespo, published at Cárdenas, Maldonado \& Gil 2007).

the high hygrothermal oscillation in geographical areas in which this type of dwelling is placed. This strategy together with the use of breezes in summertime as well as their urban planning guarantee the comfort levels in areas of high severity (Barbero, Gil, Maldonado \& Cárdenas 2013).

\section{CONCLUSIONS}

The use of a methodology for the climatic analysis applied to the analysis of the traditional or vernacular architecture shows the importance of its environmental adaptation as well as energy conservation mechanisms. The latters have their expression in several architectural elements (windows, eaves, walls, windbreaks...), and architectural types (cave-dwellings, dwellings with courtyard, compacted house...) as well as urban planning (disperse settlement, long blocks, orientation and topography adaptation...).

This paper promotes the revival and valuation of traditional architecture not only because of its cultural and historical values (preservation of buildings and the history and culture of a region) but also from a social point of view (adaptation to the lifestyle, uses and customs). In addition, traditional architecture is the expression of energy adaptation with the minimum sources. Regarding this, the analysis of climatic adequacy of this type of constructions has to take into account the building itself, its evolution and the directly and indirectly related factors. Among others, it should be considered its layout in the urban space and environmental characteristics such as geology or climate conditions. The physical, geolithological and morphological environment have influence on the selection of the settlements in terms of the most suitable for construction and the preservation of the best for agriculture uses. In addition the use of some building materials and techniques are

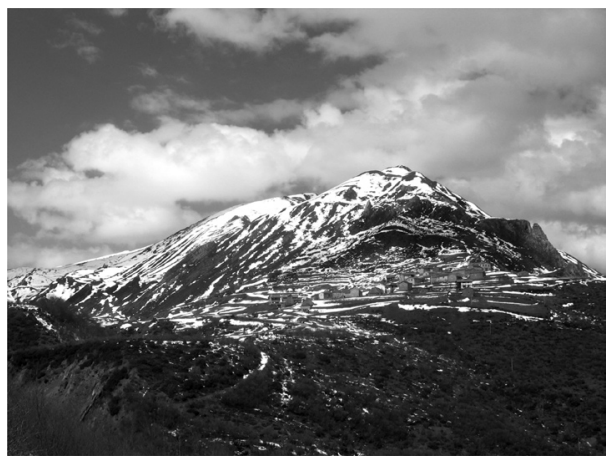

Figure 7. Mountain architectural landscape in El Peral (Asturias). (María del Mar Barbero Barrera).

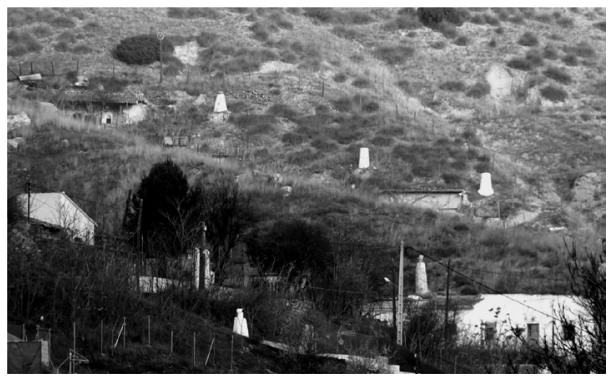

Figure 8. Neighborhood of cave-dwelling in Tielmes (Tajuña's valley, Madrid). Caves are excavated in the slope of the valley and only chimneys and façades are visible (María del Mar Barbero Barrera \& Ignacio Javier Gil Crespo).

determined by their availability. Climatic conditions such as winds, breezes, solar radiation, lighting, rainfalls and intensity and flood areas affect the location and shape of the urban settlements as well as the architecture. 
Vernacular architecture is a possible answer to the necessity of accommodation to the inhabitant of a region, which depends on the natural environment and socio-economical characteristics of the social group. Building adaptation to the social, economic and cultural changes of the rural areas is basic to avoid their abandon and inevitable wreck. Hence, vernacular architecture is not an outdated architecture and it has to be understood as a learning tool which is the result of analysis and evolution if it is analyzed with architectural awareness.

\section{REFERENCES}

Alp, A.V. 1991. Vernacular climate control in desert architecture. Energy and Buildings 16 (3-4): 809-815.

Al-Hinai, H., Batty, W.J. \& Probert, S.D. 1993. Vernacular architecture of Oman: Features that enhance thermal comfort achieved within buildings. Applied Energy 44 (3): 233-244.

Barbero Barrera, M.M., Gil Crespo, I.J., Maldonado Ramos, L. \& Cárdenas y Chávarri, J. de. 2013. Underground dwellings in the Tajuña valley (Madrid) and their bioclimatic adaptation. In Correia, M., Carlos, G. \& Rocha, S. Vernacular Heritage and earthen architecture. Contributions for sustainable development. London: CRC Press, Taylor \& Francis Group. 495-500.

Barbero Barrera, M.M. 2007. La pérdida de la arquitectura vernácula en las zonas rurales. In Actas de las Primeras Jornadas de Arquitectura Vernácula. Boceguillas. Unpublished.

Cañas, I. \& Martín, S. 2004. Recovery of Spanish vernacular construction as a model of bioclimatic architecture. Building and Environment 39: 1477-1495.

Cárdenas y Chávarri, J. de, Maldonado Ramos, L. \& Gil Crespo, I.J. 2007. Arquitectura popular de Lanzarote. Madrid: Fundación Diego de Sagredo.

Cárdenas y Chávarri, J. de, Maldonado Ramos, L., Barbero Barrera, M.M. \& Gil Crespo, I.J. 2008. Sostenibilidad y mecanismos bioclimáticos de la arquitectura vernácula española: el caso de las construcciones subterráneas. In Actas del Primer Congreso Medio Ambiente Construido y Desarrollo Sustentable. La Habana.

Cardinale, N., Rospi, G. \& Stefanizzi, P. 2013. Energy and microclimatic performance of Mediterranean vernacular buildings: The Sassi district of Matera and the Trulli district of Alberobello. Building and Environment 59: 590-598.

Gavieta, R.C. 1991. Mass housing based on traditional design and indigenous materials for passive cooling in the tropical urban climate of the Philippines. Energy and Buildings 16 (6-4): 925-932.

Gil Crespo, I.J. 2011. Arquitectura vernácula de la sierra de Gredos y el valle del Alto Tormes (Ávila). Análisis tipológico, fundamentos constructivos y funcionamiento bioclimático. Cuadernos abulenses 40: 43-76

Gil Crespo, I.J. 2014. El lenguaje vernáculo de las carpinterías tradicionales canarias: antecedentes, tipología y funcionamiento bioclimático. Anuario de estudios atlánticos 60: 817-858
Givoni, B. 1969. Man, Climate and Architecture. London: Elsevier.

Jingxia, L. 1996. The bioclimatic features of Vernacular Architecture in China, WREC: 305-308.

Luxán García de Diego, M. (ed.) 2011. Habitar sostenible. Integración medioambiental en 15 casas de arquitectura popular española. Madrid: Ministerio de Fomento.

Luxán García de Diego, M., Vázquez Espí, M., Gómez Muñoz, G., Román López, E. \& Barbero-Barrera, M.M. 2009 Actuaciones con criterios de sostenibilidad en la rehabilitación de viviendas en el centro de Madrid. Madrid: Empresa Municipal de la Vivienda y Suelo.

Maldonado Ramos, L., Castilla Pascual, F.J., Vela Cossío, F. \& Rivera Gómez, D. 2001. Rendimiento y coste energético en la construcción de cerramientos de fábrica de adobe y bloque de tierra comprimida. Informes de la construcción 53 (473): 27-38.

Matsubara, N., Nakase, I. \& Horikoshi, T. 1991. Traditional landscapes in Japan with regard to climatic, geographical and hydrological environment. Energy and Buildings 15 (3-4): 471-478.

Mazarrón, F.R. \& Cañas, I. 2009. Seasonal analysis of the thermal behaviour of traditional underground wine cellars in Spain. Renewable Energy, 34: 2484-2492.

Oliver, Paul. 2003. Dwellings. London: Phaidon.

Olgyay, V. 1998. Arquitectura y clima: manual de diseño bioclimático para arquitectos y urbanistas. Barcelona: GG.

Özdeniz, M.B. 1991. Bioclimatic analysis of traditional Turkish houses. Environmenta International 17 (4): 325-336.

Ruiz Mazarrón, F., Cid Falceto, J. \& Cañas, I. 2010. Uso de bodegas subterráneas tradicionales y modernas excavadas en tierra para la crianza de vino. In VII Congreso Internacional de Arquitectura de Tierra. Valladolid: Universidad de Valladolid.

Rudofsky, B. 1968. Arquitectura sin arquitectos. Madrid: SEAA.

Saá, C., Míguez, J.L., Morán, J.C., Vilán, J.A., Lago, M.L. \& Comesaña, R. 2011. The influence of slotted floors on the bioclimatic traditional Galician agricultural dry storage structure (horreo). Energy and Buildings, 43: 3491-3496.

Saá, C., Míguez, J.L., Morán, J.C., Vilán, J.A., Lago, M.L. \& Comesaña, R. 2012. A study of the influence of solar radiation and humidity in a bioclimatic traditional Galician agricultural dry storage structure (horreo). Energy and Buildings, 55: 109-117.

Singh, M.K., Mahapatra, S. \& Atreya, S.K. 2008. Bioclimatism and vernacular architecture of north-east India. Building and Environment 44: 878-888.

Vissilia, A.M. 2009. Evaluation of a sustainable Greek vernacular settlement and its landscape: Architectural typology and building physics. Building and Environment 44: 1095-1106.

Zhai, Z.J. \& Previtali, J.M. 2010. Ancient vernacular architecture: characteristics categorization and energy performance evaluation. Energy and Buildings 42: $357-365$. 